\title{
Humanismo, diversidad e identidad. Relecturas de José Martí en el pensamiento latinoamericano contemporáneo
}

\section{Humanism, diversity and identity. Rereading José Martí in the contemporary Latin American thinking}

\section{Humanismo, diversidade e identidade. Releituras de José Martí no pensamento latino-americano contemporâneo}

Dante Ramaglia ${ }^{1}$

Recibido: 28 de marzo de 2018 - Aceptado: 20 de abril de 2018

\begin{abstract}
Resumen:
Se examina en la obra de José Martí la relevancia que poseen sus ideas respecto a las postulaciones próximas a un humanismo pleno e inclusivo, que atiende tanto a la significación asignada a la diversidad social y cultural como a la afirmación de una identidad auténtica, lo cual es considerado como requisito para afianzar la autonomía e integración de las naciones latinoamericanas a fines del siglo XIX.

La elaboración de esta temática en el escritor cubano reviste una singularidad que se trata de presentar en relación con el momento en que inscribe sus textos más conocidos, entre los que se destaca el ensayo Nuestra América. Igualmente, interesa poner de relieve las interpretaciones que se han realizado desde el pensamiento contemporáneo, que vienen a enfatizar la vigencia de sus propuestas para la filosofía latinoamericana.
\end{abstract}

Palabras clave: José Martí - Humanismo - Diversidad - Identidad - Filosofía latinoamericana

1 Argentino. Doctor en Filosofía. Instituto de Filosofía Argentina y Americana, Facultad de Filosofía y Letras, Universidad Nacional de Cuyo / INCIHUSA-CONICET. Contacto: ramaglia@mendoza-conicet.gob.ar 


\begin{abstract}
:
The article examines José Martís work and the relevance of his ideas regarding nominations to a full and inclusive humanism addressing both the significance assigned to social and cultural diversity and the affirmation of an authentic identity, which is considered a requirement to strengthen autonomy and integration of Latin American nations at the end of the 19th Century.

The development of this theme by the Cuban writer is unique in relation to the moment in which he inscribes his most well-known texts, among which the essay Nuestra América (Our America) is highlighted. Likewise, it is interested in highlighting interpretations made from the contemporary thinking which emphasize the validity of his proposals for Latin American philosophy.
\end{abstract}

Keywords: José Martí - Humanism - Diversity - Identity - Latin American Philosophy

\title{
Resumo:
}

Examina-se na obra de José Martí a relevância que possuem as suas ideias relativamente aos postulados próximos a um humanismo pleno e inclusivo, que atende tanto à significação atribuída à diversidade social e cultural quanto à afirmação de uma identidade autêntica, o qual é considerado como requisito para assegurar a autonomia e integração das nações latino-americanas no final do século XIX.

A elaboração desta temática no escritor cubano reviste uma singularidade que se tenta apresentar em relação ao momento em que inscreve os seus textos mais conhecidos, entre os que se destaca o ensaio Nossa América. Igualmente, interessa salientar as interpretações que se têm realizado desde o pensamento contemporâneo, que vêm enfatizar a vigência das suas propostas para a filosofia latino-americana.

Palavras-chave: José Martí - Humanismo - Diversidade - Identidade Filosofia latino-americana

\section{Las ideas de José Martí en su época y sus proyecciones actuales}

La obra de José Martí se ubica en un periodo de transición que atraviesa América Latina hacia finales del siglo XIX, momento en que está concluyendo el conflictivo proceso desencadenado con las luchas de independencia en el último enclave colonial del imperio español que estaba constituido por la isla de Cuba, con cuya liberación definitiva 
se comprometió Martí en su decidida intervención política e intelectual desde su prolongado exilio hasta su muerte en combate, en 1895. En este sentido, parte de sus últimas reflexiones y escritos se vincularían con la denuncia de las consecuencias que trajo aparejado el dominio colonial, desde un juicio crítico que lo consideraba aún subsistente en las nuevas repúblicas, que se habían constituido con grandes dificultades en nuestros países. A esta situación se añadía la amenaza que comenzaba a vislumbrarse en la creciente influencia desplegada en la región por los Estados Unidos de Norteamérica, en sus intenciones de remplazar la hegemonía europea a nivel mundial. Esta circunstancia desfavorable al logro de una auténtica independencia para la comunidad de naciones de América Latina y el Caribe, advertida inicialmente por el pensador cubano, daría lugar a distintas posiciones de otros intelectuales, que reivindicaron la idea de una identidad común y el objetivo de alcanzar la unidad política; en particular, resultaría enunciado este programa con fuerza a partir de los comienzos del siglo XX. En el sostenimiento de este proyecto integracionista se combinó una actitud defensiva y al mismo tiempo afirmativa de nuestra cultura y de los diferentes sujetos sociales que configuraban una realidad compleja y heterogénea con sus características singulares. Sin entrar a detallar aquí las repercusiones que experimentaron en el momento inmediatamente posterior las ideas de Martí, interesa poner de relieve el cambio de sentido que van a instaurar de modo significativo, respecto a otras manifestaciones intelectuales y corrientes de pensamiento que constituyeron antecedentes y también en relación con las que fueron contemporáneas. Esto último puede ser considerado de acuerdo al contexto en que son producidas, principalmente en su respuesta a interpretaciones que circularon en la época, en vinculación con el proceso de modernización que se procuraba para las naciones latinoamericanas, ya sea que provinieran del discurso civilizatorio que se propició principalmente a partir del romanticismo o en la nueva versión que se sustentaba en el ideario positivista. Frente a este panorama, en su lugar, el pensador cubano promovió un proyecto emancipatorio desde el que se ofreció una vía alternativa en los planos político y cultural para profundizar la autonomía efectiva del subcontinente. 
Una nota central del pensamiento que distingue a Martí, y que ha sido subrayada por quienes se han ocupado del mismo, se relaciona con sus proposiciones próximas al humanismo. Este movimiento ha sido característico de las ideas más avanzadas que se presentan históricamente en América Latina, el cual se identifica de modo amplio por la voluntad de asignar al ser humano un valor fundamental, que se refleja en la reivindicación de los grupos humanos que habían sido subordinados a partir de la estratificación social que se impuso con la organización colonial y prosiguió en la etapa republicana. En el escritor cubano el humanismo tiene su expresión, además de lo mencionado respecto de la significación antropológica que poseen sus ideas, en la valoración de todo individuo por su dignidad intrínseca, que se traduce en la necesidad de salir en defensa de aquellos a quienes se les ha negado esta posición igualitaria o, en otros términos utilizados por él, de "hacer causa común con los oprimidos" como uno de los motivos centrales que animan su reflexión y acción. Para Martí, la construcción de las nuevas naciones requería edificarlas sobre bases que disolvieran las divisiones sociales y raciales provenientes del antiguo mundo colonial y, en cambio, proponía que se fundaran a partir del reconocimiento de las cualidades valiosas de todos sus integrantes y establecieran un marco político para garantizar esa condición de respeto a los diferentes ciudadanos que integran una misma comunidad nacional. En el caso de los países de Latinoamérica y el Caribe, esta integración social entendía que debería realizarse respecto de los sujetos que habían sido relegados ya desde el orden impuesto por la Colonia, lo cual no se había revertido totalmente en la instancia republicana, cuando esta última resulta extendida en la mayor parte de los países durante el siglo XIX. En su consideración de estas relaciones de subordinación aún vigentes, que se convertían en un motivo de impugnación ética y de impedimento para la nueva organización política y social que se pretendía para nuestras nacionalidades, sobresale la palabra a favor de la población indígena y negra de América, que había sido humillada y degradada en su humanidad, así como aboga por un cambio en la condición social de las masas empobrecidas que habitaban las ciudades y los campos; en especial, en este último ámbito la figura del campesino 
concentraba esa situación de relegamiento de vastos sectores que eran reducidos a fuerza de trabajo y vivían en la miseria ${ }^{2}$.

Este posicionamiento de Martí lo distanciaba del universo ideológico que sustentaba el afianzamiento de regímenes oligárquicos en la mayor parte de los países de la región, en que se había producido una alianza entre conservadores y liberales al finalizar el siglo XIX, anteriormente enfrentados en disputas intelectuales y fuertes conflictos por la hegemonía política. Igualmente, la creciente influencia de las doctrinas positivistas significó una indicación del respaldo que encontraron varios gobiernos en esta corriente para sus proyectos de modernización y de disciplinamiento social, descontando que también pueden encontrarse ejemplos disidentes de esta orientación que se conjugaron con las tendencias socialistas o promovieron una renovación de las bases republicanas que resultaba heredera del iluminismo. Asimismo, otro aspecto significativo del movimiento positivista, que se refiere al aporte de nuevos enfoques en el terreno de los conocimientos científicos y su aplicación, constituyó una innovación epistemológica que tuvo un fuerte impacto en el cultivo de distintas disciplinas y su enseñanza en nuestros países, lo cual fue destacado por el mismo Martí.

No obstante, desde el punto de vista que es abordado puntualmente en este artículo, interesa mencionar una forma de expresión frecuente, aunque no exclusiva, de las concepciones positivistas, que se vio reflejada en la atención prestada al factor racial en un sentido biológico y determinista respecto de los caracteres que eran asignados a distintos grupos étnicos y sociales que conformaban las naciones latinoamericanas. En tratados con una supuesta base científica o en ensayos psicológico-sociales que abundaron en esa época se abordaron muchos tópicos que recaían en la explicación según caracteres raciales

2 Desde una perspectiva que enfatiza la interculturalidad, Raúl Fornet-Betancourt ha señalado la importancia de los sectores sociales subalternos en el discurso reivindicativo sostenido por Martí. Por ejemplo, en sus referencias a la tarea a realizar mediante la revolución americana, entendía que esta debía hacerse con la participación de los indígenas y así reparar las injusticias cometidas contra ellos (Fornet Betancourt 1998a). El modo en que se ha ocupado de la población negra se trata en el ensayo: "José Martí y el problema de la raza negra en Cuba" (Fornet Betancourt 1998b 41-56). 
para dar cuenta de lo que se contemplaban como las dificultades e inadaptaciones para alcanzar el progreso de acuerdo con determinados países modélicos generalmente europeos. El anterior esquema barbarie/civilización era desplazado por un lenguaje que apelaba a una terminología pseudocientífica para indicar, mediante la remisión a la idea de raza, los problemas congénitos que conllevaban ciertos sectores de la sociedad, que precisamente habían sido subordinados desde los tiempos coloniales. A partir de este criterio de división racial, se establecían jerarquías al interior de una sociedad nacional según los diferentes grupos étnicos que la componían, o se calificaba las aptitudes para el desarrollo civilizatorio de los distintos pueblos y naciones, considerados como superiores, inferiores e, incluso, en algunos casos, hasta se los declaraba como inaptos para el progreso material e intelectual, según un parámetro que reproducía anteriores consideraciones coloniales y eurocéntricas, que ahora se revelaban como justificatorias de los neocolonialismos y de la emergencia de otras formas imperiales.

De allí resultaba que se promovieran, no sólo debido a esa mirada externa sino por las mismas élites locales, una serie de prejuicios cercanos a un crudo racismo que alentaba el "blanqueamiento" de nuestras sociedades, en términos de lo que se conoció en esa época como "eugenesia", asociada a las teorías del darwinismo social. Nos estamos refiriendo a una tematización de lo racial que se configuró como un motivo de sentido común de muchos intelectuales en ese periodo, el cual aludía a un aspecto ideológico que justificó formas de dominación. Esto no excluye que puedan encontrarse otros componentes doctrinarios del positivismo, o en sentido amplio del cientificismo, que impulsaron el avance del conocimiento en distintos campos del saber, que es posible valorar favorablemente respecto a ese momento histórico ${ }^{3}$.

3 Hemos dedicado un estudio a las diferentes expresiones que se manifiestan mediante el ensayo positivista en el caso de Argentina, tomando en cuenta la significación del discurso científico para avalar distintas posiciones ideológicas, a partir de considerar principalmente las obras de Carlos Octavio Bunge, José Ingenieros y Agustín Álvarez (Ramaglia 2006). 
Igualmente, el recurso a la raza, como factor determinante de los diferentes grados civilizatorios que poseen los pueblos en su significación a nivel mundial, constituyó un modo de considerar la cuestión de la identidad nacional a partir de escritos que generalmente se volcaron en un tipo ensayístico particular, a partir de su legitimación en un lenguaje aparentemente científico. En este sentido, la aproximación a la cuestión identitaria quedaría establecida desde una comprensión deshistorizada y en cierto modo esencialista, que asignaba lugares prefijados a los diferentes sujetos en la constitución de la misma sociedad, debido a lo cual se establecía un margen de exclusión a amplios sectores subalternos. Otra variante que fue corriente en muchos planteos, se tradujo en la imposibilidad de pensar la identidad nacional a partir de lo diverso, ya que la misma se definía de modo homogéneo a partir de un arquetipo humano, concretamente el que estaba representado por la población blanca que debía transmitir sus cualidades a los restantes sujetos raciales considerados como subhumanos.

Desde esta perspectiva, como veremos más adelante, se destaca la posición inclusiva de Martí sobre la cuestión racial. En especial, sus reflexiones sobre la integración de distintos grupos étnicos y sociales, que contempla como un proceso necesario en la formación de las nuevas nacionalidades bajo un modelo republicano radicalizado, constituyen un problema principal a considerar que lo distingue de otras posturas predominantes en su época, y lo vinculan a una excepcionalidad que se verifica en un número reducido de autores. Asimismo, el modo singular de plantear la temática de la identidad, que viene a reafirmar lo propio y su mejor conocimiento a través de la enunciación de la significación del "nosotros" y de lo "nuestro", asume la alternativa de la diversidad como un hecho y un valor que debe ser incorporado en la postulación de la necesaria unidad a lograr por los países latinoamericanos ${ }^{4}$. Esta actitud humanista, que se va

4 En Arturo Roig (2009 19-80) se encuentra un sugestivo tratamiento de las categorías del "nosotros" y de lo "nuestro", incluyendo la problemática de la unidad y la diversidad, tal como pueden ser abordadas dentro de la historia de las ideas latinoamericanas y su tratamiento filosófico. 
a mostrar a través de la acción desplegada por el pensador cubano en los campos intelectual y político, representa un motivo central de la proyección y vigencia que siguen manteniendo sus ideas en el momento actual.

\section{Significación filosófica de la obra martiana}

La obra escrita de José Martí ha recibido distintas interpretaciones según cada circunstancia histórica en que se la ha recuperado y también varía de acuerdo con las perspectivas que responden a las prácticas concretas y los ámbitos disciplinarios en que se desarrolló. Esto se observa, por ejemplo, en relación con el amplio arco de intereses que cubren los diversos escritos que contienen sus propuestas y doctrinas políticas, el novedoso registro literario en que se inscriben sus textos, el trasfondo filosófico de sus proposiciones, las referencias a la situación de Cuba y América Latina, así como sus observaciones sobre otros países y personajes históricos, tal como se da en el caso de los Estados Unidos de Norteamérica, donde residió durante un tiempo prolongado, y también respecto de Europa, acerca de la cual escribió sus famosas escenas.

Si bien es difícil realizar una separación tajante entre las distintas facetas que conviven en su intensa escritura, en la cual la prosa se aproxima a los recursos poéticos y el manifiesto político no deja de atender a una cuidada expresión literaria-, nos interesa especialmente referirnos a las vinculaciones que tiene respecto al pensamiento filosófico. En parte, esta asociación con la filosofía responde a la misma formación de Martí y se encuentra diseminada en varios de sus textos en los que se reconoce una determinada inspiración doctrinaria, si bien no se puede decir que exista el intento de desarrollar de modo sistemático un conjunto de tesis filosóficas dentro de una obra que posee de hecho un carácter fragmentario. Entre las influencias recibidas se ha señalado especialmente su orientación hacia el idealismo, que proviene mayormente de la tendencia espiritualista asociada al krausismo, filosofía originaria del alemán Krause que tuvo una vasta difusión en el medio intelectual español, donde la conocería Martí 
a partir de su residencia en ese país. El racionalismo armónico de la corriente krausista -pensamiento dialéctico que tiende a conciliar las relaciones entre el hombre, la naturaleza y Dios-, junto con la impronta ética de su comprensión acerca de los fundamentos del Derecho, la sociedad civil y el Estado, constituyeron algunos de los aspectos que van a incidir en el pensador cubano ${ }^{5}$.

Los conocimientos adquiridos por Martí acerca de la historia de la filosofía se iniciaron con sus estudios universitarios en España, y prosiguieron con la enseñanza de la filosofía a la cual se dedicó después de retornar del exilio español durante su estancia en Guatemala y México. Su posterior permanencia en Estados Unidos lo acercó a la figura de Ralph Waldo Emerson, quien profesaba un trascendentalismo que aspiraba a lograr un conocimiento intuitivo que, según afirmaba, se podía obtener directamente de la naturaleza y se reflejaba en un credo panteísta ${ }^{6}$. Igualmente, del pujante país del Norte rescató su propensión a los métodos científicos de base empirista, la misma base que se procuraba en una educación científica que tendía a la aplicación del conocimiento, así como el esfuerzo dedicado a la invención y el desarrollo de la técnica empleada para mejorar las condiciones de vida. Todos estos fenómenos, que describía con asentimiento, se vinculaban a un trasfondo positivista que los sustentaba en el momento que le es contemporáneo, rescatando a los principales inspiradores de sus bases doctrinarias, como es el caso de Auguste Comte y Herbert Spencer?

5 Cuando Martí repasa la distinta inclinación hacia el subjetivismo y el objetivismo en la filosofía moderna, llega a afirmar: "Yo tuve gran placer cuando hallé en Krause esa filosofía intermedia, secreto de los dos extremos, que yo había pensado en llamar Filosofía de relación" (Martí 2016a 87).

6 Sobre su admiración por Emerson, puede consultarse el siguiente artículo publicado con motivo de su fallecimiento: "Cartas de Nueva York expresamente escritas para La Opinión Nacional (6 de mayo de 1882)" (Martí 2016b 186-195).

7 El positivismo evolucionista de Spencer tiene una influencia marcada a partir de mediados del siglo XIX, que se extendió particularmente en Estados Unidos y América Latina, como lo advierte Martí, quien notablemente lo asocia con Emerson por sus últimos escritos que contemplan a la naturaleza y el universo animados por fuerzas que lo atraviesan: "(...) después de mirar mucho a la tierra, el filósofo inglés piensa del mundo lo que pensó otro que miró mucho al cielo, porque lo veía en sí y sobre sí, y en la tierra como en todas partes, compenetrándola y entrefibrándose 
Asimismo, por su conocimiento directo de la vida intelectual de las diferentes naciones latinoamericanas, Martí constataba la irradiación que habían tenido las diversas escuelas cercanas al positivismo, ya sean las más ortodoxas que seguían a las doctrinas de Comte -llegando a fundar iglesias positivistas, como es el caso de Brasil y Chile-, o las que se expresaban en las teorías que se asocian más cabalmente al cientificismo, en muchos casos no sólo difundidas en el ámbito universitario, sino incorporadas como soporte de políticas públicas, de instituciones oficiales e incluso de algunos ensayos constitucionales. Durante el Porfiriato en México fue marcada la influencia que ejercieron los intelectuales conocidos como "científicos"; uno de los más notables fue Justo Sierra, con quien Martí entablaría un prolongado intercambio de ideas. Al igual que lo uniría un estrecho vínculo amistoso con el cubano Enrique José Varona, colaborando con la edición y difusión de sus escritos filosóficos en los Estados Unidos ${ }^{8}$.

Aun cuando en los juicios de Martí sobre el positivismo se avalaba la renovación que promovía en los métodos seguidos para la obtención del conocimiento científico, su transferencia como técnica en distintos ámbitos de la actividad humana y las formas de enseñanza que se basan en la ciencia y en el aprendizaje práctico -a diferencia de los modos especulativos y la educación escolástica que seguía reproduciéndose en las escuelas y universidades-, no dejó de presentar reparos a algunas de sus consecuencias. Ya hemos hecho mención de las discrepancias que presentaba frente a las formas discriminatorias respecto de determinados grupos, como indios y negros, que se derivaban de la alusión a la cuestión racial enfocada desde las tesis positivistas; igualmente, no deja de advertir la creciente incidencia de esta corriente de ideas hacia el último cuarto del siglo XIX en la mayoría de nuestros países:

en ella. Herbert Spencer, cabeza de positivistas, viene a concebir el universo como lo concibe Emerson". "De Herbert Spencer", La América, Nueva York, enero de 1884 (Martí 2016c 8-9).

8 Una referencia precisa acerca de la relación que mantiene José Martí respecto del positivismo latinoamericano se encuentra en Guadarrama (2015 173-200). 
"De aquella América enconada y turbia, que brotó con las espinas en la frente y las palabras como lava, saliendo, junto con la sangre del pecho, por la mordaza mal rota, hemos venido, a pujo de brazo, a nuestra América de hoy, heroica y trabajadora a la vez, y franca y vibrante, con Bolívar de un brazo y Herbert Spencer de otro; una América sin suspicacias pueriles, ni confianzas cándidas, que convida sin miedo a la fortuna de su hogar a las razas todas, porque sabe que es la América de la defensa de Buenos Aires y de la resistencia del Callao, la América del Cerro de las Campanas y de la Nueva Troya." (Martí 1977 25)9.

El hecho que ciertamente objetaba Martí, con respecto del positivismo y de otras tendencias intelectuales que fueron incorporadas en nuestro medio, se refería especialmente a la falta de discernimiento en la adopción de doctrinas y teorías que no se ajustaban a la realidad y necesidades de nuestras sociedades. Podría señalarse que este criterio rigió la misma actitud del cubano en el marco de su propia escritura y pensamiento; la asimilación de otras ideas y estilos literarios se mediaba por la recreación que se efectuaba a partir de un sesgo personal. Si es inevitable en la tarea intelectual la referencia al aporte de otros a quienes se les reconoce un determinado valor al que debemos aproximarnos, no menos necesario resultaba para Martí llegar a producir una elaboración propia que generara un saber novedoso, más cuando se trataba de aportar soluciones a los problemas derivados de la circunstancia singular que revestía la situación de los países latinoamericanos.

El impulso que anima la obra de Martí busca alcanzar un conocimiento de sí, de un "nosotros latinoamericano", que tiene que partir precisamente de un principio crítico inmanente al propio sujeto que quiere conocer $y$, al mismo tiempo, se autoafirma en su identidad

9 El párrafo citado corresponde al "Discurso de la Sociedad Literaria Hispanoamericana (Madre América)", pronunciado el 19 de diciembre de 1889 en una velada artísticoliteraria a la que asistieron los delegados a la Conferencia Internacional Americana. Este texto compara los diferentes orígenes y destinos de la América del Norte y la América del Sur, constituyendo un antecedente inmediato de su ensayo Nuestra América. 
a partir de un reconocimiento de sí que incluye a los otros con sus diferencias ${ }^{10}$. Este punto de partida, que se encuentra enunciado en sus principales escritos, lo ha remarcado Adriana Arpini (2013) como un proceso reflexivo que procura establecer las mediaciones para alcanzar el saber acerca de la propia realidad. La actitud que orienta este autoconocimiento -en relación con el propio mundo y los demás con los que es compartido-ya se encontraba planteada en los "Apuntes y fragmentos sobre filosofía", realizados cuando Martí enseñaba esta disciplina en la Escuela Normal Central de Guatemala, durante su residencia entre 1877 y 1878, donde afirmaba:

"Puedo hacer dos libros: uno dando a entender que sé lo que han escrito los demás: -placer a nadie útil, y no especial mío.

Otro, estudiándome a mí por mí, placer original e independiente. Redención mía por mí, que gustaría a los que quieran redimirse.

Prescindo, pues, de cuanto sé, y entro en mi Ser.

¿Que qué somos? ¿Que qué éramos? ¿Que qué podemos ser?" (Martí 2016a 80).

Acerca de esta reflexión martiana sobre el sentido de la filosofía, aclara Arpini:

"El texto nos coloca ante dos programas filosóficos posibles, pero diferentes. Uno consiste en reproducir la letra de la filosofía, pero como letra muerta, como pura erudición, sin más pretensiones que una "visión monumental o anticuaria" del pasado filosófico, al que se venera como cumbres de la humanidad pero que permanece exterior a nosotros. Saber que pasa a través de nosotros sin dejar huella, sin conmovernos ni transformarnos. El otro consiste en apropiarse del

10 Arturo Roig (2009) ha denominado como "a priori antropológico" a este acto de autoafirmación y reconocimiento que se pone en juego en el pensamiento filosófico, aludiendo a su presencia en diversos autores y momentos de nuestra historia, incluido por cierto José Martí. 
poder de la palabra para decir de sí, para "redimirse", es decir -según una de las posibles acepciones de esta palabra- para liberarse." (Arpini 2013 167).

Desde la posición sobre el saber filosófico descrita en Martí surge otra característica central que presenta su pensamiento. Ya se ha mencionado su forma asistemática, que implica que no se trata de desarrollar una especulación abstracta o metafísica de la cual se derivaran axiomas, sino que sus proposiciones deben entenderse en el sentido de una racionalidad práctica. Si bien pueden encontrarse referencias a autores y escuelas filosóficas en parte de sus numerosos escritos, la potencialidad de su pensar se revela en el tratamiento de los problemas concretos que surgen de una situación vital. Más que la adscripción a una corriente determinada de ideas, el acceso a la comprensión de sus reflexiones hay que buscarlo en la relación con las circunstancias a las que se enfrenta en su trayectoria biográfica e intelectual, debido a lo cual tienen que evaluarse sus aportes filosóficos respecto de la forma en que profundizó en el conocimiento de la realidad derivada del contexto histórico en que se inscribe, no desligado de un compromiso práctico visible en él, así como, en un sentido asociado a lo anterior, en los posicionamientos que establece respecto de un entramado cultural en que se distinguen sus ideas respecto de las que corresponden a otros autores con los que mantiene un diálogo crítico.

Otra dimensión que queremos remarcar especialmente se vincula con la presencia de la obra de Martí en la filosofía contemporánea de América Latina. Son numerosas las valoraciones efectuadas acerca de su legado intelectual, debido a lo cual existe un conjunto de interpretaciones que se han producido a lo largo del tiempo, y que nos ofrecen distintas visiones de la significación de su pensamiento, tema no exento de debates ${ }^{11}$. En particular, se destacan las tesis del latinoamericanismo filosófico más reciente, que han incorporado las ideas de José Martí y nos ofrecen una determinada comprensión

11 Una síntesis de las interpretaciones sobre la filosofía que está presente en la obra de José Martí -con una especial mención de los estudios desarrollados en Cuba- se encuentra en Rivas Toll 2007. 
de su relevancia y vigencia, algunas de las cuales se han incluido en la misma lectura que ensayamos en este trabajo, de acuerdo con la problemática central que aquí se trata.

Entre los antecedentes de la importancia conferida a la obra de Martí puede mencionarse el lugar que le otorga Leopoldo Zea en la realización de lo que él denomina "proyecto asuntivo", en su planteo de una filosofía de la historia ajustada a mostrar el devenir dialéctico de las ideas latinoamericanas. En tal sentido, afirma Zea:

"Martí conoce todas estas experiencias: Cuba es también América. La América criolla, mestiza, india, negra; la de los hombres que trabajan en el campo y la de los que laboran en las ciudades. América que no es bárbara ni civilizada; simplemente la América que busca realizarse por los difíciles caminos de la libertad. De esta abigarrada América, nuestra América, habrá entonces que partir para realizar las metas expresas en sus diversos proyectos." (Zea 1987 279).

Retomar ese proyecto asuntivo significa para Zea conocer e incorporar la historia y realidad propias, bajo la idea de inclusión de los sectores sociales implicados en el marco de la formulación de una identidad latinoamericana auténtica o no enajenada.

En el caso de Arturo Roig, ya hemos hecho alusión a la temática del "nosotros" y de lo "nuestro", que tiene una marcada inspiración martiana, para ampliar luego esta consideración a otros autores, conjuntamente con la noción de "a priori antropológico", que apunta a la afirmación y reconocimiento ejercido por el sujeto, en que lo axiológico es previo al mismo despliegue del saber. Otra faceta que muestra una aproximación a las ideas de Martí se relaciona con la reflexión ética, en la que Roig recurre a la categoría de "moral emergente" para analizar la significación que posee la noción de "hombre natural" empleada por el cubano, tal como lo dice:

"El "hombre natural" martiano expresa, con su "indignación y su fuerza", la contraposición entre una ética del poder y la moralidad de la protesta, entre un mundo objetivo cons- 
truido por los amos y un mundo de la subjetividad popular que tiene como impulso a las necesidades indispensables para el cumplimiento de un valor no realizado, en este caso, el de la "vida humana" y su riqueza. Y por cierto que el logro de ese valor no se satisface en la medida en que la "necesidad humana" alcance su más elevado objeto que es siempre otro ser humano considerado como fin y no como medio." (Roig 2002 225).

Otro autor contemporáneo que ha valorado la obra martiana es Raúl Fornet-Betancourt, de quien citamos anteriormente su enfoque hermenéutico, donde sobresale la referencia a la interculturalidad. Igualmente, pone de relieve en su interpretación de la relación entre "José Martí y la filosofía", como titula uno de sus ensayos, el modo en que encarna un modelo alternativo de filosofar, en cuanto su práctica de la filosofía supone una transformación de la tradición desde un nuevo punto de partida que funda otra forma vinculada a un proceso de cambio y liberación:

"La filosofía debe así, según Martí, ser transformada en un momento de la dialéctica histórica de la liberación del hombre y de la naturaleza. De donde se sigue una consecuencia doble. Pues, por una parte, la filosofía debe romper la jaula de su propia tradición. Esto es, debe ejercerse como crítica de sí misma y liberarse de todo aquello que en su propia historia ha ido impidiéndole el ejercicio de su función histórica liberadora. Por eso entendía Martí la historia de la filosofía no en el sentido de la mera exposición, sino más bien como discusión abierta del camino recorrido y de lo alcanzado en él (...) Para poder cumplir su función de aportar a la liberación del hombre y de la naturaleza debe, por tanto, la filosofía cumplir esta tarea previa de liberación de sí misma." (Fornet-Betancourt 1998b 82).

Igualmente, se da cuenta de la intención que conduce a postular una filosofía práctica, que se dedique a resolver los problemas surgidos del contexto y la historia de nuestra América, se haga cargo de la urgen- 
cia que reviste nuestra situación y se oriente a la libertad y la justicia. Fornet-Betancourt afirma que esta dirección a la praxis del pensamiento de Martí se sustenta en dos creencias previas fundamentales: una tiene que ver con su opción -en última instancia humanista- de "hacer causa común con los oprimidos"; y la otra se relaciona con la idea de un necesario desarrollo de lo particular-diverso para alcanzar lo universal, que implica atender a los grupos étnicos excluidos, en una línea de interpretación que lo asimila a un modo de pensar inculturado.

En diversos textos dedicados a temas relativos a la filosofía latinoamericana y la historia de las ideas, el uruguayo Yamandú Acosta se ha referido a la figura de Martí y a su concepto de "Nuestra América", a partir del cual entiende que se encuentra un paradigma refundacional de esta orientación filosófica. Desde este supuesto atiende a la extensión de las tesis martianas para dar cuenta de algunas cuestiones centrales que en la actualidad son resignificadas, como son la identidad, el reconocimiento, la corporeidad, la solidaridad con los oprimidos, el sistema, que en su conjunto remiten a la problemática del sujeto (Acosta 2005a 45 y ss). En la relectura que se propone de la obra martiana se destaca especialmente su vigencia y validez para interrogar a determinadas circunstancias atravesadas en el presente, que giran especialmente en torno a discusiones sobre la filosofía y la democracia en América Latina, para lo cual se considera la presencia de puentes comunes entre la época en que escribe Martí y la nuestra, según lo expresa Acosta:

"Ello implica tener a la vista que hoy, al igual que en 1891 aunque resignificadamente, Nuestra América forma parte de un universo del discurso conflictivo, en el que diagnósticos, proyectos y pronósticos expresan la lucha por la dominación o la hegemonía, al interior de un omnicomprensivo universo social que incluye también a quienes no intervienen directamente en el debate letrado, aunque la consideración de las mediaciones diversas, así como el carácter alusivo-elusivoilusorio de lo ideológico, permite sostener con plausibilidad que tengan en el mismo algún grado de expresión o de representación." (Acosta 2005b 22). 
Este mismo artículo citado encabeza un libro posterior sobre historia de las ideas y filosofía práctica inspirado en las concepciones originales que se desprenden de "Nuestra América", bajo la intención de actualizar su significación para nuestro tiempo (cf. Acosta 2012).

Entre los estudios sobre Martí, destaca la referencia que se hace del "humanismo práctico" como nota central de sus ideas en el libro ya citado de Pablo Guadarrama (2015). La obra martiana recibe un tratamiento detallado a partir de sus definiciones conceptuales y proyecciones respecto de un programa de integración latinoamericanista, incluyendo la recepción y repercusiones que ha tenido su figura desde la instalación del proceso revolucionario cubano. Al discutir la génesis y los alcances del humanismo de este autor menciona sus raíces cristianas, que le dan una orientación amorosa hacia los demás pero no abarcan todo su contenido, así como recrea sus posibles vínculos con el socialismo de su época. En particular, lo que Martí alcanza a conocer de las tesis de Marx y especialmente a través las manifestaciones sindicales de los obreros norteamericanos que reseña en sus crónicas periodísticas. De este modo, entiende Guadarrama, se perfila una posición que se va radicalizando:

"En Martí el humanismo latinoamericano adquiere una dimensión mucho más práctica y concreta. Esto debe entenderse en su sentido planetario por dos razones significativas: 1) la propuesta de estudio científico de las condicionantes de alienación y de marginación infrahumana en que viven las mayorías en todos los pueblos del orbe, y 2) la comprensión de lo inevitable de las transformaciones revolucionarias que avalan en ocasiones la justa violencia como doloroso remedio ante la violencia injusta." (Guadarrama 2015 237).

Cabe acotar que la interpretación del pensamiento latinoamericano desde una perspectiva humanista constituye un aspecto fundamental de la propuesta que esboza Guadarrama. Esto se refleja en los supuestos teóricos que utiliza para comprender la función de la filosofía y la misma obra de Martí en este sentido, tal como lo plantea en otro escrito que reúne sus postulaciones sobre estos temas (Guadarrama 2012). 
Para cerrar este panorama de la recepción del pensamiento de José Martí en la filosofía latinoamericana, que sin duda podría extenderse a otros autores y autoras que se encuentran aludidos de modo breve o que directamente hemos dejado de lado por razones de espacio, ya que la lista es amplia, queremos tratar a través de un ejemplo las posturas que impugnan ciertos aspectos de este quehacer filosófico, incluyendo también el cuestionamiento del escritor cubano como uno de sus antecedentes principales.

Como muestra de la crítica en relación al latinoamericanismo, retomamos un artículo de Idelber Avelar (2012), que precisamente propone sustituir las representaciones sobre nuestra identidad que ha elaborado el pensamiento latinoamericano y la historia de las ideas -acusados de recurrir a formas esencialistas-por la "novedad" que aporta el enfoque de la teoría literaria al utilizar un método genealógico. En este breve pero pretencioso texto se presenta un estereotipo de la posición del rival -por ejemplo, declarando que la reivindicación de la identidad está asociada sólo al esencialismo- al cual se lo trata de derribar de un lugar privilegiado, que está ubicado, por cierto, en el ámbito discursivo de las enunciaciones sobre América Latina realizadas por el saber universitario. Es un ademán común a muchas postulaciones que aparecieron con fuerza a comienzos de este siglo, generalmente desde el campo de los estudios culturales y especialmente difundidas por la crítica literaria, pero también en el terreno filosófico, que tuvo como núcleo de irradiación la academia norteamericana y, en particular, los intelectuales "latinos" que se desempeñan en ella. No se trata de recurrir a un argumento ad hominem, ya que el autor que comentamos es brasileño y desde hace tiempo trabaja en universidades de Estados Unidos, aunque el lugar de enunciación resulta indicativo del modo en que se pretende legitimar un discurso sobre lo latinoamericano.

Sobresale en este revisionismo acerca de la construcción discursiva de la identidad, que unifica a autores del pasado y del presente, la referencia a José Martí, en quien se cifraría un error que se reitera posteriormente en la historia intelectual latinoamericana: 
"En su trabajo -decididamente anticolonial, anticonservador y anti-nostálgico en su intervención política- tuvo que recurrir, sin embargo, a una crítica estética conservadora de la mercantilización con el fin de establecer no solo el lugar del poeta en el mundo moderno, sino también la identidad de "nuestra América". Aún bastante ambiguas en Martí y plenamente consolidadas en la tradición que lo siguió, las imágenes de la absorción del arte por el mercado y de la división profesional de la labor intelectual se convirtieron para el latinoamericanismo en la metáfora privilegiada de lo originario. A lo largo del siglo XX, esta estructura narrativa post-edénica sería crucial para el discurso latinoamericanista en sus diversas modalidades." (Abelar 2012 23).

Este supuesto error se traduce también en la contraposición entre la América Latina, idealizada desde una mirada estetizante por sus valores espirituales y culturales, y la América Sajona, a la que se le asigna un crudo materialismo y utilitarismo, motivos que están más claramente presentes en el Ariel de Rodó, pero que se extiende a la mayoría de los intelectuales latinoamericanos, sin reparar demasiado en los matices de cada uno. Incluso la ausencia de distinciones en el autor que comentamos vale respecto del tema de la latinidad, que es omitido por Martí al utilizar el nombre de "Nuestra América" para diferenciarse del panlatinismo impulsado por el Imperio francés, del que se distancia igualmente Francisco Bilbao cuando, en 1856, usa por primera vez el término de "América Latina" y se continúa en su denuncia realizada en escritos posteriores ${ }^{12}$. Por cierto que el sentido que adquieren las referencias a la América del Sur hacia finales del siglo XIX y principios del XX acentúa la oposición con la América del Norte, en un contexto de creciente avance de esta nueva potencia

12 Sobre la trayectoria que registra la apelación a los nombres de "América Latina" y "Nuestra américa", y las interpretaciones que han realizado autores como Arturo Ardao, Arturo Roig, Miguel Rojas Mix y Walter Mignolo, remitimos al estudio ya citado de Adriana Arpini (2013). 
imperialista sobre la región, que es inicialmente advertido por Martí y se encuentra cuestionado en otros escritores contemporáneos a él.

No obstante, la mirada genealógica parece tender un mapa uniforme y homogéneo sobre las diversas respuestas que se han elaborado en torno al problema de la identidad, al acentuar justamente lo propio a partir de la oposición con el país del Norte, que se convierte en el símbolo de la modernización capitalista, debido a lo cual se afirma:

"No solo en Rodó, sino también en la tradición que lo siguió (Henríquez Ureña, Martínez Estrada, José Vasconcelos, Alfonso Reyes, Leopoldo Zea, Arturo Roig, etc.), el discurso de la latinoamericaneidad se remonta al enfrentamiento entre la modernización y su crítica humanista." (Id. 24).

Conciente de que se ocupa un lugar incómodo y de "mala conciencia" en esta crítica al latinoamericanismo, incluyendo los esquematismos y reduccionismos a que se ha sometido a la posición que se convierte en contraria -representada por toda una larga y variada tradición de pensamiento crítico y de crítica cultural-, la cuestión se revierte en la afirmación de la propia postura a partir de la sospecha ideológica (¿marxista?) que se vuelca injustificadamente sobre el adversario intelectual, es decir, la misma figura subjetiva y conceptual que ha inventado el discurso genealógico como opuesto:

"Las inclinaciones progresistas de la tradición latinoamericanista no pueden cegar a la genealogista: la retórica de la identidad, la retórica del "nosotros", la retórica de la inasimilable diferencia de América Latina han generado una mitología interesada en preservar su posición dentro de las jerarquías sociales y económicas del continente." (Id. 24-25).

No vamos a detenernos ahora en otras apreciaciones sobre lo que designa como la "mitificación de Martí", en especial cuando señala que esta actitud: "(...) ha impedido una percepción más clara de cómo su crítica al racismo biológico también contenía una hipostatización del 'hombre natural' en contra del ámbito de lo artificial' (Id. 25). El 
tema del hombre naturaly del modo en que se emplea el concepto de naturaleza reviste cierta complejidad que retomaremos más adelante. Algo ya se ha anticipado en las fuentes filosóficas que se reconocen en Martí, así como la posibilidad de interpretar de modo histórico la noción de "hombre natural" desde la problemática de la emergencia social, tal como lo sugiere Arturo Roig (2002).

\section{Actualidad de Nuestra América: reconocimiento y liberación}

Resulta significativo que el pensamiento contemporáneo encuentre en las ideas de José Martí una serie de claves para repensar la situación y disyuntivas a las que se enfrenta todavía el conjunto de los países latinoamericanos. Como hemos visto, sus reflexiones representaron una dislocación respecto a las orientaciones doctrinarias y formas políticas que se venían imponiendo en la conformación de los Estados nacionales cuando concluía el siglo XIX. En especial, ese programa político y cultural alternativo quedó expresado en su célebre manifiesto Nuestra América, publicado originalmente en 1891, a partir del cual es posible retomar en su contenido americanista la enunciación de un humanismo de carácter inclusivo, que viene a resignificar la dirección que debían asumir las repúblicas en su autonomía política. Su postura tenía sin duda antecedentes, pero Martí entiende que requería plantearse con fuerza ante la urgencia de modificar la postura de quienes estaban aferrados a su mentalidad "aldeana". En las palabras que inician el texto de Martí esto significaba permanecer encerrado en un mundo pequeño creyendo que es lo universal: "(...) sin saber de los gigantes que llevan siete leguas en las botas y le pueden poner la bota encima, ni de la pelea de los cometas en el cielo, que van por el aire dormido engullendo mundos. Lo que quede de aldea en América ha de despertar" (Martí 1977 26). Esta advertencia inicial se dirigía a alertar sobre la amenaza que veía cernirse sobre nuestras nacionalidades, en el contexto de la presencia creciente de los Estados Unidos de Norteamérica en la región y las disputas que este país entabla por el dominio a nivel planetario, que había tenido su epicentro 
con el reparto colonial concentrado hasta entonces por Europa. Ante este peligro externo, la prédica de Martí se presenta también como denuncia crítica de una racionalidad política que había desvirtuado el proceso independentista en las naciones latinoamericanas, para lo cual afirma que, como condición indispensable, debía erigirse sobre otros principios un nuevo sistema que redimiera a los sectores populares, esto es, un conjunto amplio que sería identificado con quienes se encuentran en la condición de oprimidos.

Un motivo central se refiere al reclamo de unidad que promueve Martí para los países de América Latina: "Es la hora del recuento y de la marcha unida, y hemos de andar en cuadro apretado, como la plata en las raíces de los Andes" (Ibíd.). Lo que demanda, además, avanzar hacia una integración de los sectores mayoritarios que habían sido relegados, tal como observa en la necesidad de incorporar a los habitantes indígenas como condición para llevar adelante una transformación radical:

“ Estos nacidos en América, que se avergüenzan, porque llevan delantal indio, de la madre que los crió, y reniegan ¡bribones!, de la madre enferma, y la dejan sola en el lecho de las enfermedades! (...) ¡Estos hijos de nuestra América, que ha de salvarse con sus indios, y va de menos a más; estos desertores que piden fusil en los ejércitos de la América del Norte, que ahoga en sangre a sus indios, y va de más a menos!" (Id. 27).

Existe una cierta ambigüedad en su discurso respecto a la situación en que se encuentran las nuevas naciones que se estaban formando en América Latina, en particular acentuada cuando se refiere a la actitud hacia la población autóctona, que oscila entre los adjetivos de la "vergüenza" y el "orgullo". Esto se hace patente cuando afirma mediante una pregunta: "Ni ¿en qué patria puede tener un hombre más orgullo que en nuestras repúblicas dolorosas de América, levantadas entre las masas mudas de indios, al ruido de la pelea con el cirial, sobre los brazos sangrientos de un centenar de apóstoles? De factores tan descompuestos, jamás, en menos tiempo histórico, se han creado naciones tan adelantadas y compactas" (Ibíd.). Es la distancia que se 
verifica entre lo que se había logrado mediante la empresa heroica de la independencia, con el auxilio de esos sectores populares, y lo que se culmina malogrando a partir del establecimiento de las nacientes repúblicas, en las que se concluye sometiendo a los distintos grupos subalternos, dentro del orden político y social que se termina de consolidar hacia el último tercio del siglo XIX, y en el cual las elites intelectuales y dirigentes justifican aun esta exclusión. En todo caso, la contradicción existe en un plano objetivo que se constata, a lo que se sobrepone un factor subjetivo y voluntario -si no perdemos de vista el carácter de manifiesto de Nuestra América- mediante el cual Martí interpela principalmente desde una aspiración ideal, que consiste en superar las divisiones sociales para alcanzar una unidad de acción, lo que implica retomar en un sentido radical el proyecto igualitario de emancipación que irrumpe con el proceso independentista.

Igualmente, puede observarse que este llamado a la unidad tiene como punto de partida y complemento necesario la afirmación de la diversidad. Para entender los alcances de la diversidad es necesario reparar en la profusión de imágenes y metáforas que se van presentando en el texto, que aluden además a niveles diferentes de comprensión de esta problemática. En una primera aproximación Martí alude a la composición heterogénea y, en cierto sentido, caótica, deformada o no plenamente constituida de nuestros países, como afirma en uno de sus pasajes: "Éramos una visión, con el pecho de atleta, las manos de petimetre y la frente de niño. Éramos una máscara, con los calzones de Inglaterra, el chaleco parisiense y la montera de España (...) Éramos charreteras y togas, en países que venían al mundo con la alpargata en los pies y la vincha en la cabeza" (Id. 30). Y en esta descripción que apela a imágenes corporales de América se presenta también la situación en que se dio principio a la lucha por la independencia: "Con los pies en el rosario, la cabeza blanca y el cuerpo pinto de indio y criollo, vinimos, denodados, al mundo de las naciones" (Id. 29). ¿Cuál era el origen de esta realidad contrastante en la apreciación que realiza Martí? En cierto modo, lo heterogéneo resulta designado como un aspecto constitutivo, que encierra además una contradicción no resuelta en la instancia anterior y en la que siguió al momento revolucionario, pero que no representa necesariamente un 
disvalor ${ }^{13}$. Para él, la identidad común no se obtiene con la búsqueda de lo uniforme que aplana las diferencias, sino con el reconocimiento de todos esos distintos factores que componen un todo que debe desarrollarse igualmente de modo armónico.

La dificultad se encuentra en el conflicto subsistente, que se desprende de la inequidad y el sojuzgamiento efectuado sobre distintos sujetos sociales, como resultado de la dominación colonial que produjo la existencia de "elementos discordantes y hostiles"; una herencia que no se había logrado revertir con la formación posterior de las repúblicas, en las que afirma que aún sigue viviendo y se prosigue luchando contra la colonia, de este modo va a decir que: "(...) la constitución jerárquica de las colonias resistía la organización democrática de la República" (Id. 29). Pero este aspecto, que había sido señalado por quienes impulsaron una emancipación mental, resulta ubicado en otro plano al denunciar la insuficiencia, no únicamente de la inadecuación de las instituciones, leyes e ideas importadas que se pretendieron imponer, sino también de la misma actitud de quienes denomina como "letrados artificiales" y "redentores bibliógenos". En definitiva, se trata de los miembros de los círculos intelectuales y políticos dirigentes, que habían desconocido los derechos de los mismos sujetos populares que participaron en las luchas por la independencia y con los cuales debía establecerse un sistema democrático alternativo, que atendiera a las necesidades y objetivos compartidos al afirmar lo común, según lo afirma contundentemente Martí:

"El continente descoyuntado durante tres siglos por un mando que negaba el derecho del hombre al ejercicio de su

\footnotetext{
13 Cabe mencionar que la tendencia a la heterogeneidad en Martí está presente en su misma concepción de la lengua y la escritura, tema que ocupa la reflexión de diversos intelectuales en el siglo XIX, tal como lo plantea acertadamente Cecilia Sánchez: "(...) Bello defiende el cuerpo viviente de la lengua para impedir su babelización, a diferencia de Darío, quien postula una hermandad cosmopolita de raros. Con esta ampliación, Darío rompe con la homogeneidad de la lengua y la cultura proyectada para Hispanoamérica. A distancia de Bello y de Sarmiento, Martí se propone recuperar los derechos del "hombre natural" y dar curso a una lengua heterogénea y libre. (Sánchez 2013 243).
} 
razón, entró, desatendiendo y desoyendo a los ignorantes que lo habían ayudado a redimirse, en un gobierno que tenía por base la razón; la razón de todos en las cosas de todos, y no la razón universitaria de unos sobre la razón campestre de otros. El problema de la independencia no era el cambio de formas, sino el cambio de espíritu.

Con los oprimidos había que hacer causa común, para afianzar el sistema opuesto a los intereses y hábitos de mando de los opresores." (Id. 29-30).

Es claro que en el panorama que traza Martí, en el que repasa los aspectos diferentes y conflictivos que componen lo americano, la superación de ese estado de cosas que proviene del mundo colonial se lograría a partir de la integración de lo diverso en la realización de un auténtico sistema republicano y democrático. Para ello era necesario que no se encubriera esa diversidad o se la asimilara en una pretendida forma universal desde la cual se justificaban las desigualdades existentes. Tal como sucedía, por ejemplo, entre quienes fomentaban una distinción a partir de lo racial, debido a lo cual negaban una humanidad plena a quienes eran asimilados a una condición de inferioridad frente a un modelo que portaba una supuesta medida de lo universal representado por el hombre blanco. Esta valoración hegemónica correspondía a la centralidad que adquiere Europa a partir de la modernidad, que resulta afianzada junto con el proceso de expansión colonial, cuyo reflejo se encuentra en la continuidad que va a conllevar su reproducción por las élites blancas de las naciones latinoamericanas.

Como ya examinamos, la apelación a la noción de "raza" se había difundido mediante la ideología positivista, que tematizó frecuentemente sobre la diferenciación jerárquica con que caracteriza a la composición de nuestras sociedades. Ante esta postura, Martí va a apuntar que sólo hay "razas de librería" y, en su lugar, sostiene la idea de una "identidad universal del hombre", para concluir en la siguiente afirmación: "El alma emana, igual y eterna, de los cuerpos diversos en forma y color. Peca contra la Humanidad el que fomente y 
propague la oposición y el odio de razas" (Id. 32). En esta apreciación habría que destacar que se parte negando legitimidad a las extendidas manifestaciones discursivas que recayeron en la noción de una "guerra de razas". Para Martí, eran elucubraciones de "pensadores de lámparas". Lo otro que sobresale es la universalidad con que se reviste a la condición humana, resignificada esta igualdad en el concepto de "alma", pero que surge a partir de la diversidad que se remite a nuestra corporalidad. Esta última noción aparece reiteradamente en el texto como lugar donde radican rasgos distintivos y registran las marcas de una identidad particular. Precisamente, entendía Martí que esas particularidades debían ser reconocidas, para ser integradas en una forma de convivencia que acentuara los aspectos comunes, de acuerdo con nuestra humanidad compartida ${ }^{14}$.

En términos políticos, para consolidar una sociedad diferente, la opción para Martí estaba planteada desde una solidaridad con los oprimidos, esto es, con las masas campesinas, la población indígena y negra, que resultaba subordinada en el proyecto civilizatorio y modernizador promovido por parte de las elites. La crítica de la deriva que se desprendía de esta orientación declinante de las mismas promesas de la revolución independentista la resumía del siguiente modo: "El genio hubiera estado en hermanar, con la caridad del corazón y con el atrevimiento de los fundadores, la vincha y la toga; en desestancar al indio; en ir haciendo lado al negro suficiente; en ajustar la libertad al cuerpo de los que se alzaron y vencieron por ella" (Id. 30). La proclamada libertad que se procuró alcanzar en los Estados nacientes no debería consistir, de acuerdo con la adopción de la concepción liberal moderna, en un reaseguro de las instituciones y leyes que consagraron un valor abstracto, sino que

\footnotetext{
14 En un escrito publicado un par de años después, emitiría un juicio similar contra quienes alentaban la diferenciación racial, así como respecto del racismo que separaba a blancos y negros en Cuba, al afirmar: "Insistir en las divisiones de raza, en las diferencias de raza, en un pueblo naturalmente dividido, es dificultar la ventura política y la individual, que están en el mayor acercamiento de los factores que han de vivir en común"; y añadía a esta consideración política otra idea que expresa su convicción profunda: "Hombre es más que blanco, más que mulato, más que negro"; cf. "Mi patria", Patria, New York, 16 de abril de 1893 (Martí 2005 15-16)
} 
recibiría su pleno sentido en la realización de los sujetos concretos que lucharon en todo caso por su liberación respecto de relaciones opresivas.

La alusión a esos sujetos se encuentra igualmente en una designación que Martí utiliza frecuentemente en su manifiesto referida al "hombre natural", también aludido como el "hombre real", enfrentado a lo que se califica como artificial. Sin duda, no dejan de presentarse dificultades en esta denominación y su asociación con el concepto de "Naturaleza" (escrita en este texto y otros con mayúsculas) ${ }^{15}$. Sin duda que no debería descuidar un escritor como él las resonancias de estos términos para referirse a lo propio de América. Como es sabido, la remisión a la naturaleza fue vinculada desde el comienzo de la colonización a lo americano y recibió un significado particular en la visión de autores como Rousseau, que intentaron mostrar otro rostro en el que se espejaba la misma civilización europea con su noción de "buen salvaje". En Martí podría observarse que esta alusión se efectúa desde la inversión de un signo valorativo de lo humano definido desde la radicalidad de su existencia material, lo cual se presenta como denuncia del artificio que pueden contener las representaciones culturales. Esto no significa una oposición entre naturaleza y cultura en términos absolutos, sino el señalamiento de una desviación operada en la esfera de lo cultural cuando esta se convierte en una forma de distinción social, tal como lo remarca en los "letrados artificiales" que desconocen a ese "hombre natural", así como a los factores naturales o reales que componen el propio

15 Sin tratar aquí detalladamente esta concepción sobre la naturaleza que aparece recurrentemente en Martí, es posible remitirla a sus fundamentos filosóficos, uno de los cuales se relaciona con el krausismo, aunque mediado por una interpretación propia que se encuentra reseñada en sus "Apuntes y fragmentos sobre filosofía", en un texto que empieza y termina del siguiente modo: "La naturaleza observable es la única fuente filosófica. El hombre observador es el único agente de la filosofía (...) Naturaleza es todo lo que existe, en toda forma -espíritus y cuerpos; corrientes esclavas en su cauce; raíces esclavas en la tierra; pies, esclavos como las raíces; almas, menos esclavas que los pies. El misterioso mundo íntimo, el maravilloso mundo externo, cuanto es, deforme o formado, luminoso u oscuro, cercano o lejano, vasto o raquítico, licuoso o terroso, regular todo, medido todo menos el cielo y el alma de los hombres- la virtud es Naturaleza" (Martí 2016a 81-84). 
país. Contra la difundida dicotomía que se había instaurado como interpretación del conflicto que atraviesa a nuestras sociedades, afirmará: "No hay batalla entre la civilización y la barbarie, sino entre la falsa erudición y la naturaleza" (Id. 28). Igualmente, esta violencia cometida contra lo que tiene una razón de ser profunda para Martí en su remisión a lo natural y lo real, se traduce en la justificación del motivo para llevar adelante la lucha por el reconocimiento que encarnan esos sujetos negados por un determinado orden impuesto, que se muestra claramente en la siguiente frase: "Viene el hombre natural, indignado y fuerte y derriba la justicia acumulada en los libros, porque no se la administra en acuerdo con las necesidades patentes del país" (Ibíd.).

Arturo Roig (2002, 223-229) realiza una interpretación de esta concepción martiana, en que la fuerza irruptora de ese ser humano revela precisamente que representa un agente histórico y no se trata de remitirlo meramente a la naturaleza. En esa figura de rebelión contra la opresión considera Roig que están simbolizados los sujetos y movimientos populares que expresan lo que caracteriza como una moralidad de la emergencia, enfrentada a una eticidad objetivada en un determinado sistema de códigos y normas de un derecho instrumentalizado desde los intereses de un sector dominante. Asimismo aclara que el "hombre natural" no sería un tipo humano exento de mediaciones culturales, ya que pone en juego una demanda de justicia en que esas mediaciones van a estar orientadas por las necesidades que responden a un principio regulador de las mismas, relativo al valor en última instancia de la vida humana.

En otras palabras, la crítica de un orden injusto se realiza desde la afirmación de los sujetos indignados que reclaman una transformación del mismo, en cuanto no contempla las necesidades que corresponden a todos sin exclusión. La vida humana, en cuanto implica la realización de acuerdo con una finalidad y valor intrínseco, implica además la cualificación como una vida digna ${ }^{16}$. En sus propios términos, este 
criterio lo expresó Martí en su famoso discurso "Con todos y para el bien de todos", pronunciado el 26 de noviembre de 1891 en Tampa, ante los partidarios del movimiento libertario cubano, en el que insistía en la necesidad de lograr la integración y de deponer cualquier forma de división, en particular las que provenían del racismo de algunos de esos inmigrantes. En este sentido, proponía como norma básica de la política futura a adoptar, que constituía igualmente un principio ético desde el cual esta se fundamenta, lo siguiente:

"Porque si en las cosas de mi patria me fuera dado preferir un bien a todos los demás, un bien fundamental que de todos los del país fuera base y principio, y sin el que los demás bienes serían falaces e inseguros, ese sería el bien que yo prefiriera; yo quiero -decía firmemente Martí- que la ley primera de nuestra república sea el culto de los cubanos a la dignidad plena del hombre." (Martí 2005 37-38).

La idea de un humanismo pleno representaba así un objetivo de la misma acción revolucionaria, sobre la cual se planeaba edificar una nueva sociedad que asegurara la condición igualitaria de todos sus miembros.

Otro tema que aparece en Nuestra América se vincula a la función que cumple el saber, lo cual remite a la tarea de los intelectuales y el lugar de la escritura, cuestiones que serían inmediatamente cercanas a Martí. En parte, se desprende de lo anteriormente mencionado que en sus apreciaciones aparece una denuncia de la figura del letrado, en cuanto este reproduce una visión deformante y, en cierto modo, mistificada de las sociedades latinoamericanas. Lo primero se refiere más que nada a un desconocimiento de lo que entiende que constituyen los "factores reales del país", y esta situación proviene de la incapacidad de los hombres cultos, que detentan un saber ajeno que no se adapta a las propias circunstancias. Para remediar esto sostiene que: "La universidad europea ha de ceder a la universidad americana. 
La historia de América de los incas a acá, ha de enseñarse al dedillo, aunque no se enseñe la de los arcontes de Grecia. Nuestra Grecia es preferible a la Grecia que no es nuestra. Nos es más necesaria" (Martí 1977 29). Una afirmación indudablemente irreverente respecto de la tradición que representarían las humanidades clásicas, lo cual no significa que se niegue la validez de ese saber, sino que la apropiación del mismo se propone desde un lugar que parte primero del conocimiento de lo propio, de lo que es más necesario, como afirma a continuación: "Injértese en nuestras repúblicas el mundo; pero el tronco ha de ser el de nuestras repúblicas" (Ibíd.). Desde otro punto de vista, viene a reafirmar la idea de que lo singular es el punto de partida para alcanzar lo universal.

Ese saber referido a lo propio tenía además una dimensión práctica, era necesario en su función política que debía asentarse en una racionalidad compartida en lo común, que significaba para Martí superar el divorcio entre la "razón universitaria" y la "razón campestre", como se mencionó anteriormente. La contraposición entre el campo y la ciudad o, como había sido postulada, entre la civilización y la barbarie, remitía igualmente a dos culturas, que debían ser llevadas a un plano superior en que una no negaría a la otra. La palabra escrita, que era representativa de la primera, resulta criticada en cuanto estaba asociada a una forma de ejercicio del poder que desconocía esa otra expresión que surgía de la oralidad o, en otros términos, contenía otro tipo de racionalidad que en su articulación a formas de saber popular requerían ser integradas en el ámbito de lo público y comunitario. A partir de la recreación de una nueva escritura, que reflejara lo espontáneo y vital para todo ser humano, va a darse la propuesta que desarrollaría Martí desde la prosa y la poesía en el movimiento precursor del modernismo, que no desembocaría en una tendencia estetizante sino que asumiría un fuerte compromiso social y, en definitiva, de valoración de lo humano en su riqueza.

Por otra parte, el conocimiento representaba para Martí una forma de aproximación a lo nuestro, en que destaca la tendencia a la creación como comienzo de un cambio cultural que se estaba realizando para llegar a comprendernos mejor: "Se ponen en pie los pueblos, 
y se saludan. '¿Cómo somos?' se preguntan; y unos y otros se van diciendo cómo son. Cuando aparece en Cojimar un problema, no van a buscar la solución a Dantzig. Las levitas son todavía de Francia, pero el pensamiento empieza a ser de América" (Id. 31). En este movimiento hacia el autoconocimiento es planteado el tema de la identidad, que resulta definido a partir de la diversidad, que está presupuesta no sólo entre las naciones latinoamericanas, sino como realidad presente en la misma constitución social y cultural existente en cada caso. Una identidad que no oculte las diferencias significa, en las palabras de Roig que hemos citado, un proceso de autoafirmación de un sujeto plural, de un "nosotros" que se identifica como latinoamericano.

En este sentido, representa la capacidad de reconocerse que tienen los sujetos a partir de una construcción cultural no enajenada, en que se pone de manifiesto, además, la posibilidad de reconocer a los demás, a quienes son negados por un discurso que continúa reproduciendo la estructura axiológica del mundo colonialista. En esta apuesta teórica y política por la emancipación social se juega un motivo principal que anima el pensamiento de Martí, cuya significación profundamente humanista persiste interpelándonos en el momento presente. El cambio significativo que propone como desafío se vincula, precisamente, al reconocimiento de las diversidades que conforman las culturas de América Latina. Desde este punto de vista, el programa político y cultural contenido en Nuestra América puede entenderse en su función utópica, alude a una tarea que requiere ser llevada continuamente a un plano de realización y es, por este motivo, todavía un proyecto que mantiene su vigencia.

\section{Bibliografía}

Acosta, Yamandú. Sujeto y democratización en el contexto de la globalización. Perspectivas críticas desde América Latina. Montevideo: Nordan-Comunidad, 2005a.

Acosta, Yamandú. "Nuestra América: vigencia y validez". Dialéctica, nueva época (Universidad Autónoma de Puebla) 29/37 (2005b): 21-36. 
Acosta, Yamandú. Reflexiones desde "Nuestra América". Estudios latinoamericanos de historia de las ideas y filosofía de la práctica. Montevideo: NordanComunidad, 2012.

Arpini, Adriana María. "América Latina / Nuestra América. El quehacer filosófico entre nosotros". Letras (Facultad de Letras y Ciencias Humanas, Universidad Nacional Mayor de San Marcos) 84/119 (2013): 143-172. Disponible en: http://revista.letras.unmsm.edu.pe/index.php/le/article/view/37/37

Avelar, Idelber. "Hacia una genealogía del latinoamericanismo". Revista Pensamiento Político (Instituto de Humanidades, Universidad Diego Portales) 2 (2012): 19-31. Disponible en: http://www.pensamientopolitico.udp.cl/ edicion-dos

Fornet-Betancourt, Raúl. "El pensamiento de José Martí. Estudio introductorio: vida y líneas generales de su pensamiento", (1998a). Disponible en: http:// www.ensayistas.org/filosofos/cuba/marti/marti2.htm

Fornet-Betancourt, Raúl. Aproximaciones a José Martí. Aachen: Concordia. Internationale Zeitschrift für Philosophie, Wissenschaftsverlag Mainz in Aachen, Bd. 24, 115, 1998b.

Giorgis, Liliana. José Martí. El humanismo como filosofía de la dignidad. Rio Cuarto: Ediciones del ICALA, 2006.

Guadarrama González, Pablo. Pensamiento filosófico latinoamericano. Humanismo, método e historia. Tomo I. Bogotá: Universidad Católica de Colombia / Planeta, 2012.

Guadarrama González, Pablo. José Martí: humanismo práctico y latinoamericanista. Santa Clara: Editorial Capiro, 2015.

Martí, José. Nuestra América. Prólogo de Juan Marinello. Selección y notas de Hugo Achugar. Cronología de Cintio Vitier. Caracas: Biblioteca Ayacucho, 1977.

Martí, José. Nuestra América y otros escritos. Prólogo de Arturo Andrés Roig. Buenos Aires: Ediciones El Andariego, 2005.

Martí, José. Obras Completas. Edición crítica. Tomo 5. 1877-1880. México, Cuba, Guatemala y Estados Unidos (volumen 1). La Habana/Buenos Aires: Centro de Estudios Martianos/CLACSO, 2016a. Publicación electrónica disponible en: https://www.clacso.org.ar/coleccion_jose_marti

Martí, José. Obras Completas. Edición crítica. Tomo 9. 1881-1882. Estados Unidos (volumen 1). La Habana/Buenos Aires: Centro de Estudios Martianos/ CLACSO, 2016b. Publicación electrónica disponible en: https://www.clacso. org.ar/coleccion_jose_marti 
Martí, José. Obras Completas. Edición crítica. Tomo 19. 1882-1884. Estados Unidos (volumen 3). La Habana/Buenos Aires: Centro de Estudios Martianos/ CLACSO, 2016c. Publicación electrónica disponible en: https://www.clacso. org.ar/coleccion_jose_marti

Ramaglia, Dante. "El ensayo positivista: interpretaciones en torno al imaginario científico". En: Argentina en el espejo. Sujeto, nación y existencia en el medio siglo (1900-1950), comp. Clara A. Jalif de Bertranou. Mendoza: EDIUNC, 2006, $127-158$

Ramaglia, Dante. "Aproximaciones a la cuestión de la diversidad desde la filosofía latinoamericana contemporánea". En: Filosofía de la convivencia, coord. Omer Buatu Batubenge, Benjamín Panduro Muñozy Adriana Mancilla Margalli México: Universidad de Colima/Ediciones Eón, 2014.

Rivas Toll, Elena. "Reflexiones en torno a la filosofía de José Martí en el contexto de la filosofía latinoamericana". A parte rei. Revista de Filosofía 49 (2007): 1-27. Disponible en: http://serbal.pntic.mec.es/ cmunoz11/rivas49.pdf

Roig, Arturo. "Ética y liberación: José Martí y el 'hombre natural". En: Ética del poder y moralidad de la protesta. Respuestas a la crisis moral de nuestro tiempo. Mendoza: EDIUNC, 2002.

Roig, Arturo. Teoría y crítica del pensamiento latinoamericano. Edición corregida y aumentada. Buenos Aires: Una Ventana, 2009.

Roig, Arturo. Rostro y filosofía de nuestra América. Edición corregida y aumentada. Buenos Aires: Una Ventana, 2011.

Sánchez, Cecilia. El conflicto entre la letra y la escritura. Legalidades / contralegalidades de la comunidad de la lengua en Hispano-América y América-Latina. Santiago de Chile: Fondo de Cultura Económica, 2013.

Zea, Leopoldo. Filosofía de la historia americana. México: Fondo de Cultura Económica, 1987. 